\title{
ANALYSIS OF THE ENERGY EFFICIENCY DESIGN INDEX FOR TWO CONTAINER SHIPS AND EEDI INFLUENCE ON PROPULSION PERFORMANCES
}

\author{
Gabriel Constantin \\ University "Dunarea de Jos" of Galati, \\ Faculty of Naval Architecture, Galati, Domneasca \\ Street, No. 47, 800008, Romania, \\ E-mail:constantingabriel19@yahoo.com
}

\author{
Mihaela Amoraritei \\ University "Dunarea de Jos" of Galati, \\ Faculty of Naval Architecture, Galati, Domneasca \\ Street, No. 47, 800008, Romania, \\ E-mail:mihaela.amoraritei@ugal.ro
}

\begin{abstract}
As a technical measure to control $\mathrm{CO}_{2}$ emissions from ships, the International Maritime Organization (IMO) has developed the Energy Efficiency Design Index (EEDI). IMO takes into consideration the technical development of all the components that influence $\mathrm{CO}_{2}$ emissions, to achieve a minimum level of energy efficiency per capacity mile for new ships. The paper is focused on Energy Efficiency Design Index calculation for two container ships: 800 TEU and 1805 TEU and analysis of EEDI requirements influence on propulsion performances. Ships propulsion systems have been designed: three main engines have been selected for each ship and the propellers have been redesigned to consume delivered power. To achieve an EEDI within standards, a balance of performances is needed between: ship capacity, power, speed, minimum fuel consumption and the smallest amount of gas emitted into the atmosphere.
\end{abstract}

Keywords: container ships, propulsion performances, $\mathrm{CO}_{2}$ emissions, EEDI regulations

\section{INTRODUCTION}

The Energy Efficiency Design Index has become an important topic in the marine industry. From the 1st of January 2013, all new ships must meet the EEDI requirements. This index has been developed by IMO and it must reflect technical issues such as: optimization of ship hull, engines and propellers or the use of non-fossil fuels. For the near future, vessels will continue to burn fossil fuels and the most important means of reducing $\mathrm{CO}_{2}$ emissions will be achieved through further improvements across the entire shipping chain. Improvements to ship hull may lead to hydrodynamic and structural hull optimisation and improvements to engine and propellers lead to higher speed, lower EEDI and low $\mathrm{CO}_{2}$ emissions.
A study by Transport \& Environment in collaboration with the IMO shows that $71 \%$ of new containers emitting a quarter of global ship's $\mathrm{CO}_{2}$ emissions already meet EEDIpost-2025-requirements. The best $10 \%$ of new container ships are already nearly twice as effective to the EEDI requirements for the next 10 years. According to a study by the IMO, three types of ships accounted for $55 \%$ of the total $\mathrm{CO}_{2}$ emissions in maritime transport: container ships (23\%), bulk carriers $(19 \%)$ and tankers $(13 \%)$, as shown in figure 1.

The paper is focused on Energy Efficiency Design Index calculation for two container ships: 800 TEU and 1805 TEU and on the analysis of EEDI requirements influence on propulsion performances. Ships propulsion systems have been designed: three main engines have been selected for each ship and 
the propellers have been redesigned to consume delivered power and to achieve maximum efficiency.

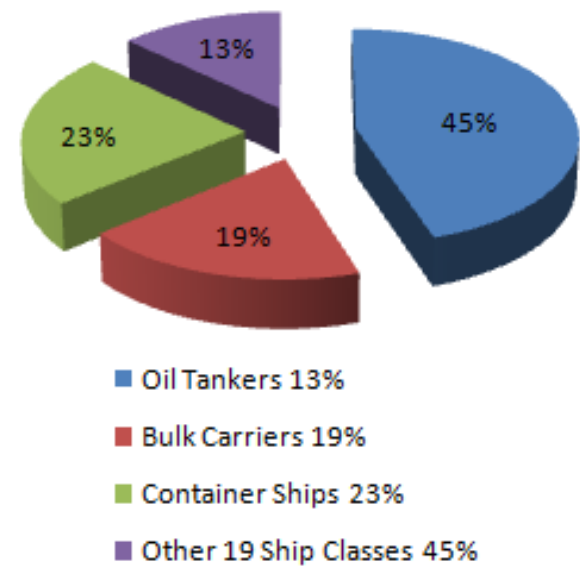

Fig. 1. $\mathrm{CO}_{2}$ emissions from global shipping

\section{GUIDELINES FOR THE ENERGY EFFICIENCY DESIGN INDEX (EEDI) CALCULATION}

Energy Efficiency Design Index is expressed as the $\mathrm{CO}_{2}$ emissions of a ship divided to the transport work carried out under the same conditions, according to the equation below:

$$
\text { EEDI }=\frac{\mathrm{CO}_{2} \text { Emission }}{\text { TransportWork }}
$$

EEDI calculation is performed using the simplified formula:

$$
\text { EEDI }=\frac{\mathrm{CO}_{2} \text { Emission }}{f_{i} * \text { capacity } * v_{\text {ref }} * f_{w}}
$$

where the $\mathrm{CO}_{2}$ emissions are given by power multiplied with $\mathrm{CO}_{2}$ conversion factor and specific fuel consumption.

Power for EEDI calculation includes the power required for propulsion and auxiliary machines. The power of the main engines is taken as $75 \%$ of the rated installed power (MCR). The auxiliary power is taken into account as a fixed proportion of the main engine power.

$\mathrm{CO}_{2}$ conversion factor depends on the type of fuel burned and SFC (Specific Fuel Consumption in $\mathrm{g} / \mathrm{kWh}$ ) represents a characteristic of the engine defined as the amount of fuel per engine power unit.

Two important parameters in EEDI formula (2) are speed and ship capacity. In the case of container ships, the capacity is defined as $70 \%$ deadweight. Ship speed measured in knots signifies an important parameter in ship design.

A reference line is developed as a curve representing the mean value of the index in a set of values for a defined group vessel.

REF.Line $=a^{*}$ Capacity $^{-c}$

The parameters a and $\mathrm{c}$ are developed according to the ship type: for container ships $\mathrm{a}=174.22$ and $\mathrm{c}=0.201$.

An attained EEDI must be lower than the required EEDI for each new ship:

Attained EEDI $\leq$ Required EEDI

Required EEDI = B

$B=\left(1-\frac{x}{100}\right) * a * 100 \% D W T^{-c}$

where $\mathrm{x}$ is a reduction factor according to year of built for new ships:

15000 DWT and above

- $\quad X=10$ - phase 1 (2015-2019)

- $\quad X=20$ - phase 2 (2020-2024)

- $\quad X=30$ - phase 3 (2025-...).

10000 DWT - 15000 DWT

- $\quad X=0$ - 10 - phase $1(2015-2019)$

- $\quad X=0$ - 20 - phase $2(2020-2024)$

- $\quad X=0$ - 30 - phase $3(2025-\ldots)$.

\section{SHIP PROPULSION PERFORMANCE ANALYSIS}

The analysis of propulsion performances considering the EEDI requirements was performed for two container ships: 800 TEU and 1805 TEU. 
Table 1. Main dimensions for 800 TEU container ships

\begin{tabular}{|c|c|c|}
\hline Length of waterline & 130.889 & {$[\mathrm{~m}]$} \\
\hline Breadth & 22 & {$[\mathrm{~m}]$} \\
\hline Draft & 7.3 & {$[\mathrm{~m}]$} \\
\hline
\end{tabular}

Table 2. Main dimensions for 1805 TEU container ship

\begin{tabular}{|c|c|c|}
\hline Length of waterline & 166 & {$[\mathrm{~m}]$} \\
\hline Breadth & 27.3 & {$[\mathrm{~m}]$} \\
\hline Draft & 8.5 & {$[\mathrm{~m}]$} \\
\hline
\end{tabular}

For propulsion performances analysis, ship resistance were computed for each container ship and the results have been plotted in Figures 2 and 3.

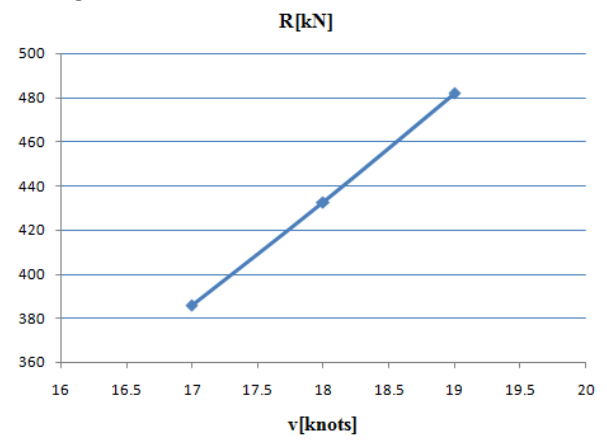

Fig. 2. Ship resistance (800 TEU)

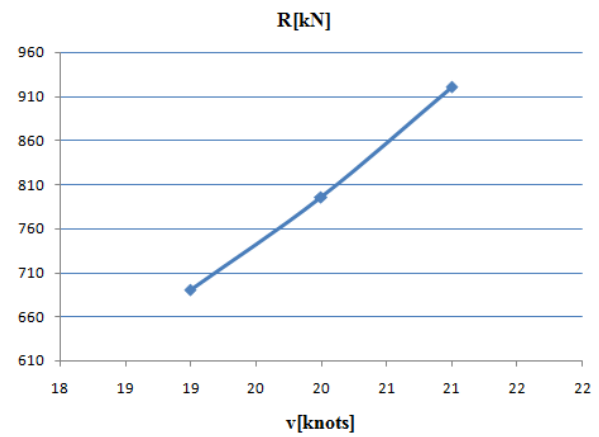

Fig. 3. Ship resistance (1805 TEU)

Ship propulsion systems were designed: three main engines were selected for each container ship size. The propellers were redesigned to consume delivered power and to give maximum efficiency. The results related to optimal propellers characteristics and ships propulsive performances are presented in tables 3-8.

Table 3. Ship/propeller propulsive performances 800TEU-case1

\begin{tabular}{|l|c|}
\hline Engine 1 MAN B\&W S46ME-B8.5 \\
\hline Brake Horsepower [kW] & 6900 \\
\hline Revolution rate [rpm] & 129 \\
\hline Number of cylinders & 5 \\
\hline Sea margin SM [\%] & 15 \\
\hline Engine margin EM [\%] & 0 \\
\hline \multicolumn{2}{|c|}{ Propeller } \\
\hline Diameter [m] & 5.217 \\
\hline Number of blades z & 4 \\
\hline Pitch ratio P/D Ship & 0.865 \\
\hline \multicolumn{2}{|c|}{} \\
\hline Speed [knots] \\
\hline
\end{tabular}

Table 4. Ship/propeller propulsive performances 800TEU-case2

\begin{tabular}{|l|c|}
\hline Engine 2 MAN B\&W S40ME-B9.5 \\
\hline Brake Horsepower [kW] & 6810 \\
\hline Revolution rate [rpm] & 146 \\
\hline Number of cylinders & 6 \\
\hline Sea margin SM [\%] & 15 \\
\hline Engine margin EM [\%] & 0 \\
\hline \multicolumn{2}{|c|}{ Propeller } \\
\hline Diameter [m] & 4.805 \\
\hline Number of blades z & 5 \\
\hline Pitch ratio P/D Ship & 0.85 \\
\hline \multicolumn{2}{|c|}{} \\
\hline Speed [knots] & 18 \\
\hline
\end{tabular}

Table 5. Ship/propeller propulsive performances 800TEU-case3

\begin{tabular}{|l|c|}
\hline Engine 3 MAN B\&W S40ME-B9.5 \\
\hline Brake Horsepower [kW] & 7945 \\
\hline Revolution rate [rpm] & 146 \\
\hline Number of cylinders & 7 \\
\hline Sea margin SM [\%] & 15 \\
\hline Engine margin EM [\%] & 0 \\
\hline \multicolumn{2}{|c|}{ Propeller } \\
\hline Diameter [m] & 4.973 \\
\hline Number of blades z & 4 \\
\hline Pitch ratio P/D Ship & 0.875 \\
\hline \multicolumn{2}{|c|}{} \\
\hline Speed [knots] \\
\hline
\end{tabular}


Table 6. Ship/propeller propulsive performances 1805TEU-case4

\begin{tabular}{|l|c|}
\hline \multicolumn{1}{|c|}{ Engine 4 MAN V48/60B } \\
\hline Brake Horsepower [kW] & 13800 \\
\hline Revolution rate [rpm] & 135 \\
\hline Number of cylinders & 12 \\
\hline Sea margin SM [\%] & 15 \\
\hline Engine margin EM [\%] & 0 \\
\hline \multicolumn{2}{|c|}{ Propeller } \\
\hline Diameter [m] & 5.846 \\
\hline Number of blades z & 5 \\
\hline Pitch ratio P/D Ship & 0.845 \\
\hline \multicolumn{2}{|c|}{} \\
\hline Speed [knots] & 19.75 \\
\hline
\end{tabular}

Table 7. Ship/propeller propulsive performances 1805TEU-case5

\begin{tabular}{|l|c|}
\hline \multicolumn{2}{|c|}{ Engine 5 MAN V48/60CR } \\
\hline Brake Horsepower [kW] & 13600 \\
\hline Revolution rate [rpm] & 127 \\
\hline Number of cylinders & 8 \\
\hline Sea margin SM [\%] & 15 \\
\hline Engine margin EM [\%] & 0 \\
\hline \multicolumn{2}{|c|}{ Propeller } \\
\hline Diameter [m] & 6.059 \\
\hline Number of blades z & 5 \\
\hline Pitch ratio P/D Ship & 0.835 \\
\hline \multicolumn{2}{|c|}{} \\
\hline Speed [knots] & 19.7 \\
\hline
\end{tabular}

Table 8. Ship/propeller propulsive performances 1805 TEU-case6

\begin{tabular}{|l|c|}
\hline \multicolumn{2}{|c|}{ Engine 6 8UEC52LSE } \\
\hline Brake Horsepower [kW] & 14400 \\
\hline Revolution rate [rpm] & 130 \\
\hline Number of cylinders & 12 \\
\hline Sea margin SM [\%] & 15 \\
\hline Engine margin EM [\%] & 0 \\
\hline \multicolumn{2}{|c|}{ Propeller } \\
\hline Diameter [m] & 6.02 \\
\hline Number of blades z & 5 \\
\hline Pitch ratio P/D Ship & 0.85 \\
\hline \multicolumn{2}{|c|}{} \\
\hline Speed [knots] \\
\hline
\end{tabular}

\section{EEDI CALCULATION}

For every study case, an attained EEDI was computed and plotted in Figures 4 to 9, according to the EEDI requirements for container ships. In these diagrams the required EEDI values correspond to Phase 1 (20152019). The results regarding Energy Efficiency Design Index for every container ship size and for different combination main engines/optimal propellers are presented in Table 9.

In the studied cases, the results were obtained by selecting different slow main engines (with different characteristics: power, specific fuel consumption, revolution rate) and by changing the speed of the vessel as a result of the optimal propeller redesign. There were no changes to the ship's hull.

Table 9. EEDI calculation results

\begin{tabular}{|c|c|c|c|}
\hline \multirow{2}{*}{ Ship } & Engine & $\begin{array}{c}\text { Required } \\
\text { EEDI }\end{array}$ & $\begin{array}{c}\text { Attained } \\
\text { EEDI }\end{array}$ \\
\hline \multirow{2}{*}{800} & Engine 1 & 25.707 & 25.031 \\
\cline { 2 - 4 } TEU & Engine 2 & 25.707 & 25.706 \\
\cline { 2 - 4 } & Engine 3 & 25.707 & 28.412 \\
\hline \multirow{2}{*}{1805} & Engine 4 & 21.014 & 21.427 \\
\cline { 2 - 4 } TEU & Engine 5 & 21.014 & 21.779 \\
\cline { 2 - 4 } & Engine 6 & 21.014 & 21.016 \\
\hline
\end{tabular}

\begin{tabular}{|c|c|c|c|}
\hline \multirow{2}{*}{ Phase } & \multirow{2}{*}{ Ship built } & \multicolumn{2}{|c|}{ Reduction factor } \\
\cline { 3 - 4 } & & $\begin{array}{c}\mathrm{dwt}_{10000} \\
15000\end{array}$ & $\begin{array}{l}\mathrm{dwt}_{15000-} \\
\text { above }\end{array}$ \\
\hline Phase 0 & $2013-2014$ & $0 \%$ & $0 \%$ \\
\hline Phase 1 & $2015-2019$ & $0-10 \%$ & $10 \%$ \\
\hline Phase 2 & $2020-2024$ & $0-20 \%$ & $20 \%$ \\
\hline Phase 3 & $2025-\ldots .$. & $0-30 \%$ & $30 \%$ \\
\hline
\end{tabular}




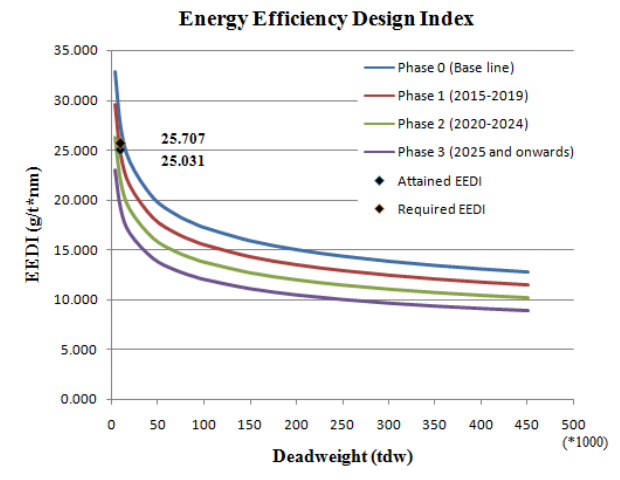

Fig. 4. EEDI - 800TEU container ship Engine 1 MAN B\&W S46ME-B8.5

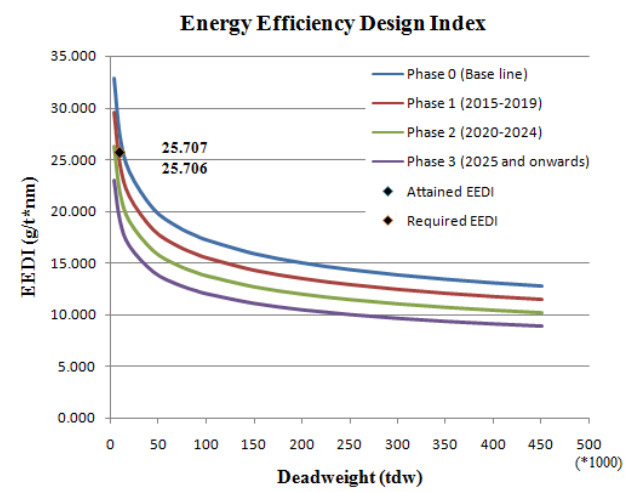

Fig. 5. EEDI - 800TEU container ship Engine 2 MAN B\&W S40ME-B9.5

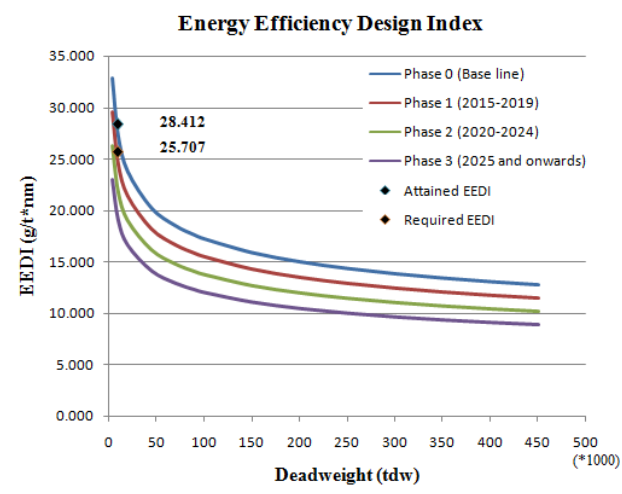

Fig. 6. EEDI - 800TEU container ship Engine 3 MAN B\&W S40ME-B9.5

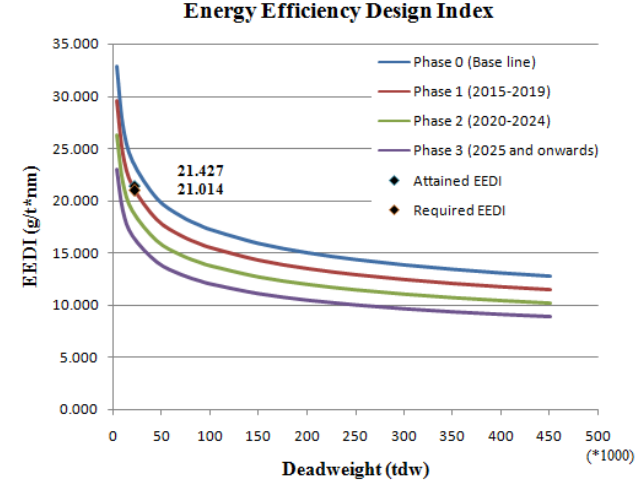

Fig. 7. EEDI - 1805TEU container ship Engine 4 MAN V48/60B

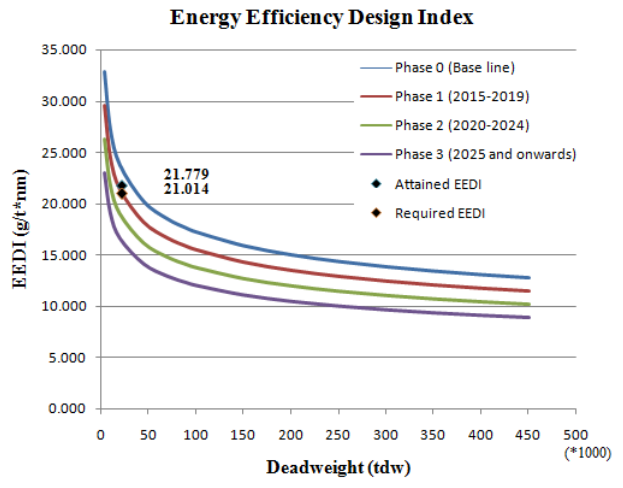

Fig. 8. EEDI - 1805TEU container ship Engine 5 MAN V48/60CR

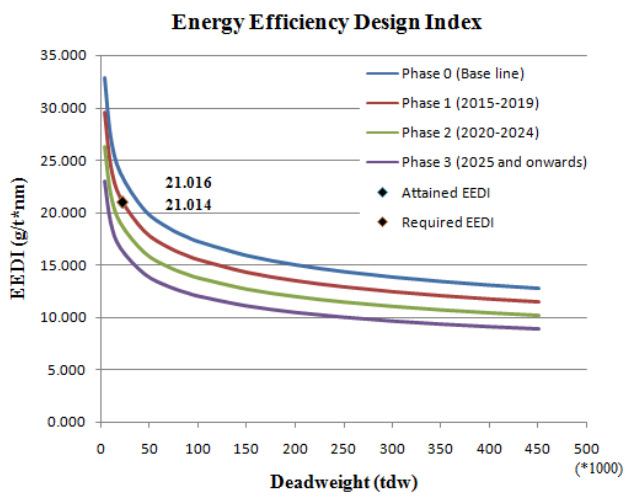

Fig. 9. EEDI - 1805TEU container ship Engine 6 8UEC52LSE 
In the first case for the 800TEU container ship, engine 1 MAN B\&W S46ME-B8.5, the attained EEDI value is greater than the required EEDI and it fits for Phase 0 (the unfavourable phase).

For the second case: 800TEU container ship, engine 2 - MAN B\&W S40ME-B9.5, the attained EEDI value $(25.706 \mathrm{~g} / \mathrm{t} * \mathrm{~nm})$ is the closest to required EEDI (25.707 $\left.\mathrm{g} / \mathrm{t}^{*} \mathrm{~nm}\right)$, at a ship speed of 18 knots, representing the required speed.

In the third case for the 800TEU container ship, engine MAN B\&W S40MEB9.5, the value of calculated EEDI is around Phase 0 .

For the 1805TEU container ship, engine 4 - MAN V48/60B and engine 5 - MAN V48/60CR, the attained EEDI values are slightly higher than required EEDI and thus it falls into Phase 0 .

The last case, for $1805 \mathrm{TEU}$ container ship, engine 6 8UEC52LSE, gives a relatively good value for attained EEDI (21.016 $\left.\mathrm{g} / \mathrm{t}^{*} \mathrm{~nm}\right)$ compared to the EEDI required $\left(21.014 \mathrm{~g} / \mathrm{t}^{*} \mathrm{~nm}\right)$. The disadvantage of the last case is that after the design of the optimal propeller a lower speed than that required was achieved.

\section{CONCLUDING REMARKS}

Considering the ship and the propulsion plant as a complex system, it is very important to find, from the initial design stages, the best combination ship/ main engine/ propeller to achieve a good balance from propulsion performances point of view: ship speed, cargo area, low fuel consumption, low emissions.

The Energy Efficiency Design Index has become an important topic in the marine industry, index which can be reduced by various technologies (deck paint, pipe insulation, lighting, air conditioning, etc.); hull shapes adjustment and less structural mass, optimal combination engine/propeller.

The paper includes an analysis of propulsion performance for two container ships taking into account EEDI regulations. Six slow diesel engines have been selected and propellers have been redesigned to consume delivered power with maximum efficiency.

The EEDI requirements have not been met in all cases, even if speed performances have been achieved. For the second case, 800TEU container ship, engine 2, the attained EEDI value is in agreement with EEDI rules (Phase 1) and shipowner's requirements by getting the necessary speed. The reduction factor is based on deadweight and it can be chosen for container ships between 10000-15000 dwt. In this case EEDI can be obtained easier according to EEDI regulations.

\section{Acknowledgements}

The present research was performed in the frame of the Naval Architecture Research Centre from the Naval Architecture Faculty of Galati.

\section{REFERENCES}

[1]. http://www.theicct.org

[2]. Longva, T., "CO2 emissions from ships", $D N V$

[3]. Indian Register of Shipping, "Implementing Energy Efficiency Design Index $(E E D I)$ "

[4]. Germanischer Lloyds Additional Rules and Guidelines, "Guidelines for Determination of the Energy Efficiency Design Index"

[5]. International Maritime Organization, "Ship Energy Efficiency Regulations and Related Guidelines".

[6]. Amoraritei, M., Domnisoru, L., Popescu G., "Ship Propulsive Performance Assessment and GHG Emissions Requirements", ICTTE 2018.

Paper received on December $15^{\text {th }}$, 2018 